\title{
Nonconventional opponents: A review of malaria and leishmaniasis among United States Armed Forces
}

\author{
Kaylin J Beiter ${ }^{1}{ }^{\text {, }}$ Zachariah J Wentlent ${ }^{1}{ }^{\text {, Adrian R Hamouda }}{ }^{1}{ }^{\text {， Bolaji Thomas }}{ }^{\text {Corresp. }}{ }^{1}$ \\ ${ }^{1}$ Biomedical Sciences, Rochester Institute of Technology, Rochester, NY, United States of America \\ Corresponding Author: Bolaji Thomas \\ Email address: bntsbi@rit.edu
}

As the United States military engage with different countries and cultures throughout the world, personnel become exposed to new biospheres as well. There are many infectious pathogens that are not endemic to the US, but two of particular importance are Plasmodium and Leishmania, which respectively cause malaria and leishmaniasis. These parasites are both known to cause significant disease burden in their endemic locales, and thus pose a threat to military travelers. This review introduces readers to basic life cycle and disease mechanisms for each. Local and military epidemiology are described, as are the specific actions taken by the US military for prevention and treatment purposes. Complications of such measures with regard to human health are also discussed, including possible chemical toxicities. Additionally, poor recognition of these diseases upon an individual's return leading to complications and treatment delays in the United States are examined. Information about canine leishmaniasis, poorly studied relative to its human manifestation, but of importance due to the utilization of dogs in military endeavors is presented. Future implications for American health regarding malaria and leishmaniasis are also presented. 
1

2

3

4

5

6

7

8

9 \# contributed equally

10

11

12

13

14

15

16

17

20

21

22

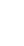

2

\section{Nonconventional Opponents: A Review of Malaria and}

\section{Leishmaniasis Among United States Armed Forces}

\#*Kaylin J. Beiter, ${ }^{\# Z}$ Zachariah J. Wentlent, ${ }^{* *}$ Adrian R. Hamouda, ${ }^{++}$Bolaji N. Thomas

Department of Biomedical Sciences, College of Health Sciences and Technology, Rochester Institute of Technology, Rochester NY

* MD-PhD Program, Louisiana State University Health Sciences Center, New Orleans

** University of Buffalo Primary Care Research Institute

Zachariah J. Wentlent: zxw9400@rit.edu

Kaylin J. Beiter: kjb3685@rit.edu

7 Adrian R. Hamouda: arh7409@rit.edu

Bolaji N. Thomas: bntsbi@rit.edu 


\section{$23{ }^{++}$Corresponding author:}

24 Dr. Bolaji N. Thomas

25 Department of Biomedical Sciences

26 Rochester Institute of Technology

27153 Lomb Memorial Drive

28 Rochester NY 14623

29 Office: (585) 475-6382

30 Fax: (585) 475-5809

31 Email: bntsbi@rit.edu

32

33

34

35

36

37

38

39

40

41

42

43

44

45 


\section{Abstract}

47 As the United States military engage with different countries and cultures throughout the world, 48 personnel become exposed to new biospheres as well. There are many infectious pathogens that 49 are not endemic to the United States but to which deployed personnel are potentially exposed. Of 50 these, Plasmodium and Leishmania, which cause malaria and leishmaniasis respectively, are of

51 importance because of the significant disease burden in endemic locales, thereby posing a major 52 threat to military travelers. This review examines local and military epidemiology of these

53 diseases, and specific actions by United States military targeted towards prevention and 54 treatment. Potential complications associated with such measures with regard to human health 55 are also discussed, including possible chemical toxicities. In addition, the fact that these diseases 56 are relatively less studied in the United States despite their global significance lends credence to 57 the poor recognition among deployed service men and women and their healthcare providers, 58 resulting in unfortunate clinical complications and treatment delays. Information about zoonotic 59 visceral leishmaniasis, poorly studied in United States relative to its human manifestation, but of 60 importance due to the utilization of dogs in military endeavors is presented. Future implications

61 for American healthcare system regarding malaria and leishmaniasis are discussed.

62

63 Running Title: Parasitic diseases among United States military 64

65 Keywords: Military, parasites, malaria, leishmaniasis, United States

66

67 Introduction 
68 International deployment is a common occurrence in United States (US) Armed Forces,

69 comprising of the Marine Corps, Navy, Air Force and Army, with nearly 200,000 troops

70 currently stationed overseas (Bialik, 2017). Leaving the US and its native biosphere for their

71 posted sites introduces a risk of exposure to, and infection with endemic parasitic, bacterial, viral

72 or fungal diseases (Ciminera and Brundage, 2007). Such hazards are well-known; during World

73 War I, approximately half a million allied soldiers were diagnosed with malaria in just one year

74 (Beaumier et al., 2013; Brabin, 2014). As United States alters its current foreign stance, engaging

75 with new regions in the process, deployment locations shift accordingly, with infectious disease

76 risks paralleling the revisions in political alignment. Most recently, US troops have been highly

77 clustered in the Middle East and Africa, specifically Iraq and Afghanistan, with sprinkling of

78 Special Forces operatives in Syria. Endemic diseases in this Middle Eastern region are caused by

79 an amalgam of local viruses, parasites, and bacteria, with the most clinically relevant including

80 Middle East Respiratory Syndrome (MERS), dengue fever, schistosomiasis,

81 enterotoxigenic Escherichia coli (ETEC), leishmaniasis, brucellosis, and toxoplasmosis (Hotez et

82 al., 2012, Humphrey et al., 2016; Raad et al., 2018, Foster et al., 2018). These pathogens, beyond

83 disease complications, have significantly impacted local economic development, limited

84 infrastructure, and reduced life expectancy of nationals causing an ever-increasing reliance on

85 pharmaceuticals (Hui et al., 2018; Park et al., 2018). Consequently, these same pathogens have

86 negatively affected members of the US military stationed at such locations (Faulde et al., 2008;

87 Fukuda et al., 2011), both with regard to direct infection of troops as well as limitations in

88 treatment accessibility.

89 
90 High infection rates of parasitic diseases, principally malaria and leishmaniasis, are expected in

91 these locales, and the deployed members of United States military have not been spared

92 (Mitchell et al., 2007; Mace et al., 2018; O’Donnell et al., 2018), with infectious diseases

93 proving to have devastating effects on the military, even contemporarily (Armed Forces Health

94 Surveillance Branch, 2018). Since initiation of the activities in the Middle East, injuries

95 sustained in battle were six times less common than those caused by non-battle injuries (i.e.

96 infection). However, the possibility for disease is not limited to deployed troops. The risk of

97 bioterrorism, domestic or foreign, from increasingly radical groups is growing all over the world

98 (Anderson et al., 2005; Beaumier et al., 2013), leading to the expansion of disease prevention

99 and force protection strategies by the Department of Defense. These efforts are subject to

100 budgetary restrictions and cuts to research funding, despite overall increase in military spending,

101 and could have serious health implications beyond the United States military (Beaumier et al.,

102 2013).

103

104 Despite the vast number of clinically relevant pathogens in locales where members of the US

105 military are deployed, this review will address only two of such infections: malaria and

106 leishmaniasis. The seriousness of these diseases and their implications for healthcare system

107 within the homeland demands critical analysis, and form the basis for this review. Due to the

108 chronic and sometimes relapsing nature of these diseases, infected individuals may present

109 symptoms months/years after exposure (Goodrich et al., 2017; Nagarajan and Sloan, 2015),

110 especially following subsequent immune system compromise (Mansueto et al., 2014). Possible

111 re-emergence of pathogenic forms in such individuals allows them to serve as agents of

112 autochthonous infections at home. 


\section{Survey Methodology}

115 For the purpose of this review, we divided the article into sections and disease-specific

116 subsections, focusing on specific diseases, one at a time. To access relevant and related

117 publications, we carried out a search on pubmed.gov for armed forces deployment information,

118 using AND as the link word, as the case may be. For others, we searched journal specific or

119 government websites (www.health.mil), in addition to websites of international organizations

120 such as World Health Organization (who.int/tdr), Centers for Disease Control (www.cdc.gov), to

121 retrieve articles focused on parasitic diseases in specific endemic locations. Subject directed

122 keywords or terms utilized in our search include armed forces, deployment, malaria,

123 leishmaniasis, epidemiology, military-related autochthonous parasitic diseases, prevention and

124 treatment. References include articles directly relating to research data, relevant case reports or

125 clinical presentations in the United States, Canada, or Europe from deployed service men and

126 women. Of additional interest in our search were articles relating to zoonotic (canine)

127 leishmaniasis among military dogs deployed overseas alongside their handlers and potential for 128 disease transmission on return to the United States.

130 Malaria

131 Despite clinical notoriety and insidiousness of more 100 years, the availability of modern

132 preventative measures and a better understanding of disease dynamics, the worldwide threat of

133 malaria in endemic countries and menace among deployed members of the armed forces

134 remains. At its apex in the Middle East, the United States Armed Forces suffered an incident rate 135 of 52.4 cases per 1,000 troops (Beaumier et al., 2013). Of recent, there has been a significant 
136 reduction in the number of troops stationed in these locations and the implementation of

137 evidence-based preventative measures against malaria. Despite this, an update from 2017 reveal

13832 cases of malaria infection among US military stationed overseas, with cases reported from

139 facilities as far as Afghanistan, Korea, Japan, Djibouti (Armed Forces Health Surveillance

140 Branch, 2018). Though the percentage of individuals affected was not given, the total reduction

141 in malaria cases in recent years has been ascribed to US troops leaving the Middle East region

142 (Armed Forces Health Surveillance Branch, 2018). This number however does not include self-

143 limited or subclinical cases, and the true attack rate may be higher than published.

144

145 Causes

146 Human malaria is spread via bloodmeals of the female Anopheles mosquito, which picks up 147 gametocytes while feeding on infected individuals, and hosts the developmental stages until full 148 maturation into infective sporozoites, which are then passed on to a new host during another 149 mosquito feeding process (Anderson et al., 2005). Clinical malaria is classically due to any of 150 four different Plasmodium (P) species: P. vivax, P. falciparum, P. ovale and P. malariae, though 151 an animal species, $P$. knowlesi has been confirmed as responsible for significant human 152 infections in parts of southeast Asia (Muller and Schlangehauf, 2014; Millar and Cox-Singh, 153 2015; Divis et al., 2015). The dominant species causing infection among the armed forces is $P$. 154 vivax (Ciminera and Brundage, 2007), although the latest update on malaria in the military shows 155 a shift to increasing infections with P. falciparum, as the causative agent for the most number of 156 cases (Armed Forces Health Surveillance Branch, 2018), likely due to the locations of reporting. 157 P. vivax, found primarily in Asia and Latin America, and in some parts of Africa, differs from 158 other species in that its life cycle includes a dormant liver stage, during which transformed 
159 parasites (otherwise called hypnozoites), can remain for months or even years after the initial

160 mosquito bite, becoming symptomatic if the parasites leave the liver to invade healthy red blood

161 cells (Baird et al., 2016), and responsible for relapses. It is uniquely dangerous in that infected

162 patients may remain subclinical for years after returning home from military service (Kotwal et

163 al., 2005), serving as agents of future autochthonous infection. Furthermore, because malaria is

164 no longer endemic in the United States, healthcare providers may see a patient presenting with

165 symptoms similar to flu symptoms, without suspecting malaria as the potential cause of such

166 clinical symptoms. This leads to delays in diagnosis and institution of appropriate treatment.

167

168 The symptoms of $P$. vivax malaria are consistent with all types of malaria: fever, chills,

169 nausea/vomiting, myalgia, fatigue, and general malaise (Yohannes et al., 2016), with infection

170 and lysis of red blood cells during the active erythrocytic cycle leading to jaundice and anemia

171 (Markus, 2011). The liver hypnozoites do not all have an equal duration of senescence, and

172 patients may experience paroxysmal symptomology, as parasites enter into active erythrocyte

173 infection at different times (Baird et al., 2016). Such a vague presentation with common

174 symptoms of general malaise often leads to misdiagnosis in the United States, where flu and

175 other common ailments are worked up instead (Evans et al., 2014; Goldman-Yassen et al., 2016).

176

177 Prevention and Treatment

178 United States military prioritizes prevention over treatment, implementing several protocols to

179 this effect, which theoretically should make it almost impossible for service members to get

180 malaria (Kotwal et al., 2005; Shaha et al., 2013). According to military documentation, there are

181 five major malaria prevention strategies namely: (1) use of factory-treated uniforms; (2) regular 
182 application of $N, N$-diethyl-meta-toluamide (DEET) or picaridin to exposed skin; (3) proper

183 wearing of military uniform; (4) use of permethrin-treated bed net, and (5) continuous

184 chemoprophylaxis during all phases of deployment (Robert, 2001). Successful implementation of

185 all five strategies however, is rare, limiting the efficacy of disease prevention. Furthermore,

186 employment of such prophylactic measures, especially with mefloquine, subjects servicemen and

187 women to significant adverse outcomes (Adshead, 2014).

188

189 Permethrin is an insecticide that kills mosquitoes by inducing spasms and paralysis (Isaacs et al.,

190 2017), while DEET, created by United States Army in 1946, is less insecticidal, masking human

191 scent to prevent mosquito bites (Toynton et al., 2009). Despite inclusion in malaria prevention

192 programs, both chemicals have known associated dangers (Diaz 2016). DEET is known to have

193 heightened toxicity when applied with sunscreen (Yiin et al., 2015; Rodriguez and Maibach,

194 2016), a situation likely to arise for military personnel deployed to tropical and subtropical

195 regions of the world. Additionally, synergism has been observed during simultaneous exposure

196 to DEET and permethrin, leading to neuronal degeneration and significant neurobehavioral

197 effects (Abdel-Rahman et al., 2004).

198

199 The chemoprophylactic drugs (doxycycline or mefloquine) administered by the military, also

200 have known adverse effects, associated with use. Historically, mefloquine was developed by the

201 US military (Nevin et al., 2005), but is now only considered if doxycycline is not tolerated. The

202 side effects can be extreme, including psychiatric symptoms such as anxiety, paranoia,

203 depression, hallucinations, and psychosis (Tan et al., 2011). Sequelae can also mimic post-

204 traumatic stress disorder (PTSD), a condition for which deployed servicemen are at high risk 
205 (Eick-Cost et al., 2017). Doxycycline is by far safer and more reliable; side effects rare, and

206 when present can range from nausea/vomiting and esophagitis to psychiatric symptoms like

207 depression and anxiety (Brisson and Brisson, 2012).

208

209 Until recently, infection with $P$. vivax malaria was treated with primaquine for complete

210 pathogen eradication. It acts by targeting the dormant hypnozoites in the liver, preventing the

211 possibility for recurrence, thereby facilitating complete recovery (Ashley et al., 2014). Adverse

212 effects have been documented in patients with rare preexisting genetic conditions such as

213 glucose-6-phosphate dehydrogenase deficiency (Valencia et al., 2016; Dombrowski et al., 2017;

214 Watson et al., 2018). Otherwise, the side effect profile is mild and comparable to all other anti-

215 malarial drugs: nausea, vomiting, and abdominal cramps (Burgoine et al., 2010). Recently,

216 tafenoquine was approved by the United States Food and Drug Administration for the

217 radical cure of vivax malaria in patients aged 16 years and older (Rajapaske et al., 2015; Tenoro

218 et al., 2015), though some genetic contraindications still exist. Both primaquine and tafenoquine

219 should be made available for the treatment of United States military servicemen and women

220 deployed overseas (Watson et al., 2018).

221

222 Leishmaniasis

223 More than twenty Leishmania species have been identified, and the parasite is considered

224 endemic throughout the world, including much of the Middle East (Golding et al., 2015). Since

225 2001, 2.4 million US troops have been deployed to Iraq and Afghanistan to participate in various

226 military missions (Spelman et al., 2012). With a 2.1\% contraction rate, leishmaniasis has become

227 one of the most commonly diagnosed diseases since the commencement of military activities in 
228 both countries (Beaumier et al., 2013). As deployed personnel return home, US cases of

229 leishmaniasis have risen to match levels seen during World War II (Weina et al., 2004).

230 Leishmaniasis is clinically relevant for armed forces and refugees alike, as civil conflict and

231 unrest continues in the Middle East.

232

233 Causes

234 The number of animal species which can serve as Leishmania reservoir hosts is ever increasing, 235 including rodents, canines, and farm animals (Stephens et al., 2016). Leishmaniasis was not 236 traditionally considered endemic to the United States, although recent epidemiologic findings

237 reveal this status may be changing, secondary to globalization and autochthonous infections

238 leading to persistent endemicity, especially along the southern border and new animal hosts

239 (Wright et al., 2008; Barry et al., 2013; McIlwee et al., 2018). Incidence and disease burden are

240 higher in societies where people live in close proximity to host animals (Henry et al., 2015).

241 Similar to malaria, it is a vector-borne disease, requiring a phlebotomine sand fly to pick up

242 amastigotes during a bloodmeal from an infected (reservoir) host. Amastigotes undergoes

243 development and maturity in the fly, which then inoculates infective promastigotes into a new

244 mammalian host during the next blood meal. Disease manifests as 3 distinct clinical forms:

245 cutaneous (including diffuse cutaneous form), mucocutaneous, or visceral. Cutaneous

246 leishmaniasis (CL) has been the most diagnosed of the three among deployed United States

247 servicemen and women ( Weil, 2010; Beaumier, et al, 2013), with L. major, the most prevalent

248 (Herwaldt et al., 1999). Overall, 90\% of global CL cases occur in Afghanistan, Brazil, Iran, Peru,

249 Saudi Arabia, and Syria. With the United States military active involvement and troop

250 deployment to these locations, increased cases of leishmaniasis were recorded, until drawdown 
251 when the number of deployed soldiers reduced dramatically (Shirian et al., 2013; Henry et al.,

252 2015). Expectedly, this is not unique to US military, with cases of L. major infection and

253 multiple reports of cutaneous disease among British, Dutch, and German soldiers as well (Faulde

254 et al., 2008; Bailey et al., 2012).

255

256 Symptoms

257 Each disease pattern has its own set of symptoms and thus differs in severity. Lesions can be

258 self-resolving, as is often the case with many instances of CL, with or without resultant

259 subclinical parasitemia (Micallef et al., 2014; Rosales-Chilama et al., 2015; Thomaidou et al.,

260 2015). The parasite can also disseminate into internal organs, as in visceral leishmaniasis,

261 becoming fatal in the process. IL-12 and CD4+ Th1 cells have especially been implicated in the

262 development of cellular immunity, though the mechanisms and explicit contributions of each are

263 not yet fully understood (Engwerda et al., 2004; McCall et al., 2013; Buxbaum, 2015; Portela et

264 al., 2018). Fortunately, CL has been the dominant clinical form in the US military, though many

265 subclinical cases, which do not require medical treatment occur as well (Reithinger et al., 2007).

266 The infection first manifests as a simple, non-swollen, red ring around the bite from the sand fly.

267 As the host immune system continues to respond locally at the bite site, sores develop on the skin

268 and can further ulcerate, causing discomfort, but generally painless (Reithinger et al., 2007). In

269 severe cases, these sores can develop on mucosal membranes, degrade the tissues of the mouth

270 and tongue, and potentially interfere with swallowing or cause difficulty breathing. The

271 incubation period for CL can range from 2 weeks to many months and even years, with potential

272 delay between contraction of the disease and onset of symptoms. Soldiers may travel between

273 countries, or even back to the United States, unwittingly becoming reservoir hosts in the process 
274 (Nagarajan and Sloan, 2015; Goodrich et al., 2017), leading to delay in diagnosis and institution

275 of appropriate treatment, if symptoms occur after the patient has returned to a non-endemic area.

276

277 Prevention and Treatment

278 The incidence rate of leishmaniasis among United States Armed Forced was 7.2 cases per

279100,000 person-years for the period of 2001 to 2016 , with the majority of cases being CL

280 (Stahlman et al., 2017). The reduced incidence rate of recent years has been attributed to better

281 equipment and an emphasis on personal protective measures (Rowland et al., 2015).

282 Nevertheless, there is still a cause for concern when troops are newly deployed to endemic

283 regions; supportive resources may not be fully in place, deployed personnel may have limited

284 knowledge, and a culture of preventative measure necessity may not have yet developed

285 (Coleman et al., 2006). All of these factors can lead to an initial high caseload (Ore et al., 2015).

286 The first line of protection from CL is through the use of personal protection techniques.

287 However, there are no effective chemoprophylaxis drugs and no fully developed vaccines, and

288 thus prevention of CL can be extremely difficult (Ghorbani and Farhoudi, 2018).

289

290 The preventative techniques that do exist focus on avoiding the bite of infected sandflies.

291 Uniforms are impregnated with a type of pyrethroid (usually permethrin), insect repellants are

292 recommended, and personnel are given pyrethrin-treated bed nets (WHO, 2018). Theoretically,

293 these measures should bring the incidence rate to near-zero levels, but this has not been the case

294 so far. In 2003 alone, the incidence rate was estimated at 200 per 1,000 soldiers (Gonzalez et al.,

295 2017). Efforts have also begun to be focused on reducing the population of sandflies, in order to

296 mitigate transmission risk. Cyfluthrin, a pyrethroid insecticide, has been used to decimate sand 
297 fly populations, and chloropiricin, a wide-spectrum nematicide and insecticide, has been used to

298 reduce the rodent (leishmania reservoir) population (Aronson et al., 1998; Crum, 2005).

299

300 Fortunately, modern medicine has afforded CL cure rates up to $91 \%$. The most effective

301 treatment is sodium stibogluconate, given intravenously at doses of $20 \mathrm{mg}$ per kilogram of body

302 weight, for 20 days (Mitchell et al., 2007; Stahlman et al., 2017), with side-effects such as

303 fatigue, arthralgia, myalgia, headaches, and chemical pancreatitis. Sodium stibogluconate is

304 efficacious, but development of new drugs is imperative due to these side effect, the threat of

305 drug resistance, and the high cost (\$100 per $100 \mathrm{~mL})$ (Aronson et al., 1998). The threat posed by

306 recent reports of treatment failures in South and Latin America leishmaniasis cases, including the

307 induction of transmissible skin microbiota that significantly promotes inflammation, should be a

308 concern for all in the infectious disease community, particularly the military (Mans et al., 2016;

309 Obonaga et al., 2016; Gimblet et al., 2017).

310

311 Other: Military Zoonotic Leishmaniasis

312 Canines are one of the main reservoirs for Leishmania species (Burza et al., 2018; Quinnell \&

313 Courtenay 2009), with cases often subclinical. As the parasite multiplies in an asymptomatic

314 dog, Leishmania is perpetuated locally via phlebotomine vectors (Kilian et al., 2007). The

315 usually implicated species, L. infantum, does not typically infect healthy humans, though

316 incidence of associated infection and disease has increased in recent years (Stoeckle et al., 2013;

317 Kroidl et al., 2014; Bennai et al., 2018; Herrera et al., 2018; Risueno et al., 2018; Teimouri et al.,

318 2018), with immunodeficient individuals at a higher risk of disease ( Michel et al., 2011).

319 Zoonotic transmission of L. infantum to humans often results in visceral leishmaniasis infection 
320 (Burza et al., 2018). Though military personnel often have superior baseline health ratings

321 compared to their civilian cohorts upon deployment, the stress of military life can contribute to

322 development of an immunodeficiency state. Additionally, military personnel are at higher risks

323 of smoking/alcohol/substance-abuse initiation and recidivism, frequently spend long periods of

324 time in environments with sub-standard hygiene, may have more erratic sleep schedules, and

325 overall suffer greater declines in mental and physical health (Dau et al., 2009; Spelman et al., 326 2012). In particular, personnel who have served in the Middle East since the Persian Gulf War

327 have reported higher levels of psychosomatic/psychological pain in comparison to cohort

328 military personnel that served contemporarily but in other locations (Gray et al., 1996; Dlugosz

329 et al., 1999). Thus, troops are at a relatively high risk of zoonotic canine leishmaniasis due to

330 exposure (military dogs becoming infected, local dogs in endemic areas) and high prevalence of 331 immunodeficiency/extreme stress secondary to their service.

332

333 Canine Leishmaniasis (CanL) is a common veterinary problem worldwide, with recent

334 prevalence estimates as high as 25-80\% (Michel et al., 2011; Akhtardanesh et al., 2017; Baneth

335 et al., 2017; Guven et al., 2017; Ruh et al., 2017; Al Bajalan et al., 2018; Monteiro et al., 2018).

336 Brazil is known to be especially affected (Borja et al., 2016; Torres-Guerrero et al., 2017; da

337 Rocha et al., 2018; Melo et al., 2018), with published reports highlighting increases in diagnoses 338 and advocating for better public health strategies to be focused specifically on dogs (Camargo 339 and Langoni, 2006; Lima et al., 2010). The armed forces regularly use military working dogs 340 (MWD) for special operations, including abroad in Leishmania-endemic regions. CanL has been

341 found multiple times in military animals (Kawamura et al., 2010; Davoust et al., 2013). Of

342 domestic importance, these dogs who are deemed 'adoptable' are mandated to return to the US, 
343 with adoption priority given to their former handlers. Approximately 1,000 former-MWDs enter

344 the US annually (Kilian et al., 2007), potentially serving as a reservoir for Leishmania: both

345 symptomatic and asymptomatic canines have been shown to have similar inoculation abilities

346 (Moshfe et al., 2009), and CanL prevalence has been shown to correlate with that of human

347 disease (Bruhn et al 2018). CanL was first found in the United States in the 1980s and 1990s

348 infecting foxhounds, (Enserink, 2000; Petersen, 2009), with limited studies carried out since, to

349 estimate current levels. Autochthonous infection has been reported since in North American dogs

350 (Schantz et al., 2005). Without better screening for all MWDs, the possibility remains for import

351 of CanL via former-MWDs and thus future augmentation in L. infantum incidence in US civilian

352 and military populations. Canine vaccination, one possible solution to mitigating CanL disease

353 burdens in the United States has shown some success as a human health preventative measure

354 (Palatnik-de-Sousa et al., 2009; Rezvan and Moafi, 2015; Ribeiro et al., 2018), though vaccine

355 efficacy remains low (68-71\%) (Ribeiro et al., 2018), questioning their utility for preventive 356 purposes.

\section{Future Implications}

359 Global political alignments often shift, and the US military remains mobile in response, with a

360 higher likelihood that a greater number of troops may be deployed to the Middle East in response

361 to current trends. Engagement with local leishmania and malaria-endemic regions puts American

362 servicemen and women at risk of disease contraction, thereby highlighting the disease burden in

363 these foreign countries.

364

365 Malaria 
366 Malaria is endemic to much of the world, and the United States military will likely continue to

367 engage in endemic areas. Drug-resistant strains of malaria have been found, indicating the need

368 for further preventative measures (Fukuda et al., 2011; Cui et al., 2015). Most of these species

369 are found in Asia (White et al., 2014). Globalization of the Asian continent as well as potential

370 future military involvement in Asia could result in military exposure to such species, resulting in,

371 at a minimum complicated treatment. For example, $P$. vivax is endemic to North Korea (Nishiura

372 et al., 2018), and though present rapprochement between both countries and South Korea seems

373 to have downplayed the threat of military engagement, US troops still engage in military runs in

374 neighboring South Korea. This puts US troops at risk of exposure if military forces press north.

375 Furthermore, malaria was eradicated in South Korea in the 1970s, but soldiers (and increasingly,

376 civilians as well) have been diagnosed with $P$. vivax malaria in the North-South demilitarized

377 zone (Lee et al., 2002; Im et al., 2018), including reports of natural hybridization between local

378 mosquito species and changing meteorological factors, to further perpetuate current observation

379 (Choochote et al., 2014; Phasomkusolsil et al., 2014; Chang et al., 2016; Hwang et al., 2016).

380

\section{Leishmaniasis}

382 CL is found primarily in the Middle East, and the US military continues to be at risk of infection.

383 The Leishmania disease burden in the Middle East is estimated at 100,000 cases annually,

384 indicating that exposure risk remains significant (Salam et al., 2018). Iran and Pakistan are of

385 note in this region: both countries steadily trending towards increased prevalence, opposite of

386 most other neighboring nations (Rahman et al., 2010; WHO, 2018). True infection rates may be

387 greater than reported due to the fact that majority of affected rural communities lack the

388 infrastructure for precise diagnosis and reporting, and the persistent antagonistic attitude to 
389 healthcare workers arising from many years of counterintelligence activities and breakdown of

390 trust. Ongoing civil conflicts in Syria compounds the growing and untenable numbers of

391 individuals symptomatic for disease or sub-clinically infected, showing up as refugees and

392 present clinically in North America, Europe and other countries (Koltas et al., 2014; Saroufim et

393 al., 2014; Bradshaw and Litvinov, 2017; Wollina et al., 2018; Mockenhaupt et al., 2016). This

394 further compounds disease status among deployed servicemen and women returning to the West,

395 igniting the need for expanding infectious disease experts into current healthcare system, as well

396 as revising medical school curriculum to include training on 'exotic' tropical or subtropical

397 diseases.

398

399

400 Conclusions

401 Parasitic diseases are common worldwide, and exposure is common in most deployment

402 locations of the United States military. The majority are not yet preventable with vaccines, and

403 the treatments and prophylaxis that are available are accompanied by many side effects. It is

404 important to continue funding for the treatment and eradication of infectious diseases worldwide

405 for many reasons, including the exposure danger posed to the armed forces. Significantly, the

406 possibility that these pathogens can be imported into the United States by returning service men

407 and women, unknowingly serving as reservoir hosts, should serve as an alarm bell for us to re-

408 evaluate, refocus and strategize how to face the challenges of the 21 st century military

409 deployment, protecting them from local pathogenic insults that can potentially lead to epidemics

410 in the homeland.

411 


\section{Acknowledgements}

413 Bolaji Thomas is supported by a Research Laboratory and Faculty Development Award, College

414 of Health Sciences and Technology, Rochester Institute of Technology. Additional funding from

415 Miller Chair in International Education (BNT) is acknowledged. The views expressed are those 416 of the authors and not necessarily those of the Rochester Institute of Technology.

417

418 Author Contributions

419 BNT conceived the idea; KJB, ZJW and AH gathered materials and wrote the manuscript; KJB,

420 ZJW and BNT edited and contributed to scientific content. All authors read and approved the

421 final version of the manuscript.

422 Conflict of Interest

423 The authors declare we have no conflicts of interest.

424

425 References

426 Abdel-Rahman A, Dechkovskaia AM, Goldstein LB, et al. Neurological deficits induced by

427 malathion, DEET, and permethrin, alone or in combination in adult rats. J Toxicol

428 Environ Health A 2004; 67(4):331-356

429 Adshead S. The adverse effects of mefloquine in deployed military personnel. J R Nav Med Serv.

430 $2014 ; 100: 232-237$

431 Akhtardanesh B, Sharifi I, Mohammadi A, Mostafavi M, Hakimmipour M, Pourafshar NG.

432 Feline visceral leishmaniasis in Kerman, southeast of Iran: Serological and molecular

433 study. J Vector Borne Dis. 2017; 54(1):96-102 
434 Al-Bajalan MMM, Niranji SS, Al-Jaf SMA, Kato H. First identification of L. major in a dog in 435 an endemic area of human cutaneous leishmaniasis in Iraq: molecular and phylogenetic 436 studies. Parasitol Res. 2018; 117(2):585-590

437

438

439

440

441

442

443

444

445

446

447

448

449

450

451

452

453

454

455

Anderson AD, Smoak B, Shuping E, Ockenhouse C Petrucelli B. Q fever and the US military. Emerging Infectious Diseases 2005; 11:1320-1322

Armed Forces Health Surveillance Branch. Update: malaria, US Armed Forces, 2017. Medical Surveillance Monthly Report 2018; 25:2-7

Aronson, N E, et al. Safety and Efficacy of Intravenous Sodium Stibogluconate in the Treatment of Leishmaniasis: Recent U.S. Military Experience. Clinical Infectious Diseases 1998; 27(6):1457-1464

Ashley, E. et al. Primaquine: the risks and the benefits. Malaria Journal. 2014; 13:418

Bailey, MS, et al. Outbreak of Zoonotic Cutaneous Leishmaniasis with Local Dissemination in Balkh, Afghanistan. Journal of the Royal Army Medical Corps. 2012; 158:225-228

Baneth G, Yasur-Landau D, Gilad M, Nachum-Biala Y. Canine leishmaniosis caused by Leishmania major and Leishmania tropica: comparative findings and serology. Parasit Vectors. 2017;10(1):113

Baird K, et al. Diagnosis and Treatment of Plasmodium vivax Malaria. Am J Trop Med Hyg 2016; $95(6$ supp):35-51

Barry MA, Weatherhead JE, Hotez PJ, Woc-Colburn L. Childhood parasitic infections endemic to the United States. Pediatric clinics of North America 2013; 60(2):471-485

Beaumier CM, Gomez-Rubio AM, Hotez PJ, Weina PJ. United States military tropical medicine: extraordinary legacy, uncertain future. PLoS Negl Trop Diseases 2013; 7(12):e2448 
456 Bennai K, Tahir D, Lafri I, Bendjaballah-Laliam A, Bitam I, Parola P. Molecular detection of

457 Leishmania infantum DNA and host blood meal identification in Phlebotomus in a

458 hypoendemic focus of human leishmaniasis in northern Algeria. PLoS Negl Trop Dis

$459 \quad 2018 ; 12: \mathrm{e} 0006513$

460 Bialik K. US active-duty military presence overseas is at its smallest in decades. Pew Research

461 2017; http://pewrsr.ch/2v2Gf3o

462 Borja LS, Sousa OMF, Solca MDS, Bastos LA, Bordoni M, Magalhaes JT, Larangeira DF, Barrouin-Melo SM, Fraga DBM, Veras PST. Parasite load in the vlood and skin of dogs

464 naturally infected by Leishmania infantum is correlated with their capacity to infect sand

465 fly vectors. Vet Parasitol 2016; 229:110-117

466

467

468

469

470

471

472

473

474

475

476

477 Burza S, Croft SL, Boelaert M. Leishmaniasis. Lancet. 2018;392(10151):951-970 $2014 ; 13: 497$

Bradshaw S, Litvinov IV. Dermal leishmaniasis in a 25-year-old Syrian refugee. CMAJ 2017; 189:E1397

Brisson M, Paul Brisson. Compliance with antimalaria chemoprophylaxis in a combat Zone. Am J Trop Med Hyg 2012; 86(4):587-590

Bruhn FRP, Morais MHF, Cardoso DL, et al. Spatial and temporal relationships between human and canine visceral leishmaniasis in Belo Horizonte, Minas Gerais 2006-2013. Parasit Vectors 2018; 11:372

Burgoine KL, Bancone G, Nosten F. The Reality of Using Primaquine. Malaria Journal 2010; $9: 376$ 
478 Buxbaum LU. Interleukin-10 from T cells, but not macrophages and granulocytes, is required for 479 chronic disease in Leishmania mexicana infection. Infect Immun 2015; 83:1366-71

480 Camargo LB, Langoni H. Impact of leishmaniasis on public health. J. Venom. Anim. Toxins 481 incl. Trop. Dis. 2006; 12:527-548

482 Chang KS, Yoo DH, Ju YR, Lee WG, Roh JY, Kim HC, Klein TA, Shin EH. Distribution 483 of malaria vectors and incidence of vivax malaria at Korean army installations near 484 the demilitarized zone, Republic of Korea. Malar J. 2016; 15:259

485

486

487

488

489

490

491

492

493

494

495

496

497

498

499

500 support natural hybridization between Anopheles sinensis and Anopheles kleini (Diptera: Culicidae): possibly a significant mechanism for gene introgression in sympatric populations. Parasit Vectors 2014; 7:36

Ciminera P, Brundage J. Malaria in U.S. military forces: a description of deployment exposures from 2003 through 2005. Am J Trop Med Hyg 2007; 76:275-9

Coleman RE, Burkett DA, Putnam JL. Impact of phlebotomine sandflies on US military operations at Tallil air base, Iraq: 1. Background, military situation, and development of a leishmaniasis control program. J Med Entomol. 2006; 43:647-662

Crum, N. History of U.S. Military Contributions to the Study of Parasitic Diseases. Military Medicine 2005; 170(4 supp):17-29

Cui L, Mharakurwa S, Ndiaye D, et al. Antimalarial drug resistance : literature review and activities and findings of the ICEMR network. Am J Trop Med Hyg 2015; 93(3 suppl):5768

da Rocha ICM, Dos Santos LHM, Coura-Vital W, da Cunha GMR, Magalhães FDC, da Silva TAM, Morais MHF, Oliveira E, Reis IA, Carneiro M. Effectiveness of the Brazilian 
501

502

503

504

505

506

507

508

509

510

511

512

513

514

515

516

517

518

519

520

521

522 Enserink M. Has Leishmaniasis become endemic in the U.S.? Science 2000; 290:1881-1883

visceral leishmaniasis surveillance and control program in reducing the prevalence and incidence of Leishmania infantum infection. Parasit Vectors. 2018; 11(1):586

Dau B, Oda G, Holodniy M. Infectious complications in OIF/OEF veterans with traumatic brain injury. Journal of Rehabilitation Research and Development 2009; 46:673-684

Davoust B, Roqueplo C, Parzy D, et al. A twenty year follow-up of canine leishmaniosis in three military kennels in southeastern France. Parasit Vectors 2013; 6:323

Diaz JH. Chemical and plant based insect repellents: efficacy, safety, and toxicity. Wilderness Environ Med 2016; 27(1):153-163

Divis PC, Singh B, Anderios F, Hisam S, Matusop A, Kocken CH, Assefa SA, Duffy CW, Conway DJ. Admixture in humans of two divergent Plasmodium knowlesi populations associated with different macaque host species. PLoS Pathog 2015; 11:e1004888

Dlugosz LJ, Hocter WJ, Kaiser KS, et al. Risk factors for mental disorder hospitalization after the Persian Gulf War : US Armed Forces, June 1, 1991 - September 20, 1993. J Clin Epidemiol. 1999;52(12):1267-1278

Dombrowski JG, Souza RM, Curry J, Hinton L, Silva NRM, Grignard L et al. G6PD deficiency alleles in a malaria-endemic region in the Western Brazilian Amazon. Malar J 2017; $16: 253$

Eick-Cost AA, Hu Z, Rohrbeck P, Clark LL. Neuropsychiatric outcomes after Mefloquine exposure among US Military service members. Am J Trop Med Hyg 2017; 96:159-166.

Engwerda CR, Ato M, Kaye PM. Macrophages, pathology and parasite persistence in experimental visceral leishmaniasis. Trends in Parasitology 2004; 20:524-530

PeerJ reviewing PDF | (2018:08:30853:1:0:NEW 29 Nov 2018) 
523 Evans AB, Kulik D, Banerji A, Boggild A, Kain KC, Abdelhaleem M, Morris SK. Imported

524 pediatric malaria at the Hospital for Sick Children, Toronto, Canada: a 16 year review.

$525 \quad$ BMC Pediatr 2014; 14:251

526 Faulde M, et al. Zoonotic Cutaneous Leishmaniasis Outbreak in Mazar-e Sharif, Northern Afghanistan: An Epidemiological Evaluation. International Journal of Medical

528 Microbiology 2008; 298.5: 543-50

529 Foster JT, Walker FM, Rannals BD, et al. African lineage Brucella melitensis isolates from $530 \quad$ Omani livestock. Front Microbiol 2018; 8:2702

531 Fukuda MM et al. Malaria and other vector-borne infection surveillance in the U.S. Department of Defense Armed Forces Health Surveillance Center-Global Emerging Infections Surveillance program: review of 2009 accomplishments. BMC Public Health 2011; 11 (Suppl 2): S9

535 Gimblet C, Meisel JS, Loesche MA, Cole SD, Horwinski J, Novais FO, Misic AM, Bradley CW 536 et al. Cutaneous leishmaniasis induces a transmissible dysbiotic skin microbiota that promotes skin inflammation. Cell Host Microbe 2017; 22(1):13-24.e4

538 Ghorbani M, Farhoudi R. Leishmaniasis in humans: Drug or vaccine therapy? Drug Des Devel 539 Ther. 2018; 12:25-40

540 Goldman-Yassen AE, Mony VK, Arguin PM, et al. Higher rates of misdiagnosis in pediatric 541 patients versus adults hospitalized with imported malaria. Pediatr Emerg Care.

542 $2016 ; 32(4): 227-231$

543 Golding N, Wilson AL, Moyes CL, Cano J, Pigott DM, Velayudhan R, Brooker SJ, Smith DL,

544 Hay SI, Lindsay SW. Integrating vector control across diseases. BMC Med. 2015; 13:249 
545 Gonzalez AM, Solís-Soto MT, Radon K. Leishmaniasis: Who uses personal protection among 546 military personnel in Colombia? Annals of Global Health 2017; 83(3-4):519-523

547 Goodrich ES, Sears SC, Sorrells T, et al. A case of cutaneous Leishmaniasis guyanensis $548 \quad$ mimicking otitis externa. Military Medicine 2017; 7:e1969

549 Gray GC, Coate BD, Anderson CM, et al. The postwar hospitalization experience of US veterans 550 of the Persian Gulf war. N Engl J Med. 1996;335(20):1505-1513

551 Guven E, Avcioglu H, Cengiz S, Hayirli A. Vector-Borne pathogens in stray dogs in 552 Northeastern Turkey. Vector Borne Zoonotic Dis. 2017; 17(8):610-617

553 Henry, J. et al. Cutaneous Leishmaniasis: Recent Developments in Diagnosis and Management. 554 American Journal of Clinical Dermatology 2015; 16(2):99-109

555 Herrera G, Higuera A, Patino LH, Ayala MS, Ramirez JD. Description of Leishmanias species 556 among dogs and humans in Colombian visceral leishmanisis. Infect Gen Evol 2018;

557 $64: 135-138$

558 Herwaldt, BL. Leishmaniasis. The Lancet. 1999; 354:1191-1199

559 Hotez PJ, Savioli L, Fenwick A. Neglected tropical diseases of the Middle East and North 560 Africa: review of their prevalence, distribution, and opportunities for control. PLoS Negl $561 \quad$ Trop Dis 2012; 6(2):e1475

562 Hui DS, Azhar EI, Kim YJ, Memish ZA, Oh MD, Zumla A. Middle East respiratory syndrome 563 coronavirus: risk factors ad determinants of primary, household, and nosocomial transmission. Lancet Infectious Diseases 2018; pii: S1473-3099(18)30127-0

565 Humphrey JM, Cleton NB, Reusken CB, et al. Dengue in the Middle East and North Africa: a 566 systemic review. PLoS Negl Trop Dis. 2016; 10:e0005194 
567 Hwang SM, Yoon SJ, Jung YM, Kwon GY, Jo SN, Jang EJ, Kwon MO. Assessing the impact of

568 meteorological factors on malaria patients in demilitarized zones in Republic of Korea.

$569 \quad$ Infect Dis Poverty 2016; 5:20

570 Im JH, Huh K, Yoon CG, Woo H, Lee JS, Chung MH, Klein TA, Jung J. Malaria control and

571 chemoprophylaxis policy in the Republic of Korea Armed Forces for the previous

572 years (1997-2016). Malar J. 2018; 17:295

573 Isaacs AT, Lynd A, Donnelly MJ. Insecticide-induced leg loss does not eliminate biting and

$574 \quad$ reproduction in Anopheles gambiae mosquitoes. Sci Rep 2017; 7:46674

575 Kawamura Y, Yoshikawa I, Katakura K. Imported leishmaniasis in dogs, US military bases,

$576 \quad$ Japan. Emerg Infect Dis 2010; 16:2017-2019

577 Koltas IS, Eroglu F, Alabaz D, Uzun S. The emergence of Leishmania major and Leishmania

578 donovani in southern Turkey, Transactions of The Royal Society of Tropical Medicine

$579 \quad$ and Hygiene 2014; 108:154-158

580 Kotwal RS, Wenzel RB, Sterling RA, Porter WD, Jordan NN, Petruccelli BP. An outbreak of

581 malaria in US Army Rangers returning from Afghanistan. JAMA 2005; 293:212-6

582 Kroidl A, Kroidl I, Bretzel G, Loscher T. Non-healing old world cutaneous leishmaniasis caused

583 by L. infantum in a patient from Spain. BMC Infectious Diseases. 2014; 14:206-209

584 Lima LV, Carneiro LA, Campos MB, Chas EJ, Laurenti MD, Corbett CE et al. Canine Visceral

585 Leishmaniasis due to Leishmania (L.) infantum chagasi in Amazonian Brazil:

586 Comparison of the parasite density from the skin, lymph node and the visceral tissues

587 between symptomatic and asymptomatic, seropositive dogs. Rev Inst Med Trop Sao

$588 \quad$ Paulo 2010; 52(5): 259-65 
589 Lee JS, Lee WJ, Cho SH, Ree HI. Outbreak of vivax malaria in areas adjacent to the 590 demilitarized zone, South Korea 1998. Am J Trop Med Hyg 2002; 66:13-17

591 Mace KE, Arguin PM, Tan KR. Malaria surveillance-United States, 2015. MMWR Surveillance $592 \quad$ Summaries 2018; 67:1-28

593 Malaria Field Guide. Army Public Health Center. USAFRICOM. May 2016

594 Mans DR, Kent AD, Hu RV, et al. Monitoring the response of patients with cutaneous

595 leishmaniasis to treatment with pentamidine isethionate by quantitative real-time PCR, 596 and identification of Leishmania parasites not responding to therapy. Clin Exp Dermatol. $597 \quad 2016 ; 41(6): 610-615$

598 Mansueto P, Seidita A, Vitale G, Cascio A. Leishmaniasis in travelers: a literature review. Travel 599 Med Infect Dis 2014; 12(6):563-581

600

Markus, M B. Malaria: Origin of the Term 'Hypnozoite'. J Hist Biol 2011; 44(4):781-786

601

McCall LI, Zhang WW, Matlashewski G. Determinants for the development of visceral

602 leishmaniasis disease. Plos Pathogens 2013; 9:e1003053-e1003059.

603 McIlwee BE, Weis SE, Hosler GA. Incidence of endemic human cutaneous leishmaniasis in the 604 United States. JAMA Dermatol 2018; 154(9):1032-1039

Melo SN, Teixeira-Neto RG, Werneck GL, Struchiner CJ, Ribeiro RAN, Sousa LR, de Melo 607 MOG, Carvalho Júnior CG, Penaforte KM, Manhani MN, Aquino VV, Silva ES, Belo VS. Prevalence of visceral leishmaniasis in a population of free-roaming dogs as

608 609 determined by multiple sampling efforts: A longitudinal study analyzing the effectiveness of euthanasia. Prev Vet Med. 2018; 161:19-24

610 Micallef C, Azzopardi CM. Atypical cutaneous leishmaniasis in the immunosuppressed. BMJ Case Rep 2014; pii: bcr2014204914 
612

613 Michel G, Pomares C, Ferrua B, Marty P. Importance of worldwide asymptomatic carriers of

614 Leishmania infantum (L. chagasi) in human. Acta Tropica 2011; 119:69-75

615 Millar SB, Cox-Singh J. Human infections with Plasmodium knowlesi-zoonotic malaria. Clin $616 \quad$ Microbiol Infect 2015; 21:640-648

617 Mitchell ME, Silvitz LB, Robert Black (eds). Infectious diseases diagnosed in US troops who 618 served in the Persian Gulf War, Operation Enduring Freedom, or Operation Iraqi 619 Freedom. In: Gulf War and Health: Volume 5: Infectious Diseases. National Academies $620 \quad$ Press, 2007, pp 4-99

621 Mockenhaupt FP, Barbre KA, Jensenius M, Larsen CS, Barnett ED, Stauffer W, Rothe C, 622 Asgeirsson H, Hamer DH, Esposito DH, Gautret P, Schlagenhauf P. Profile of illness in Syrian refugees: A GeoSentinel analysis, 2013 to 2015. Euro Surveill.

624 2016;21(10):30160

625

626

Monteiro FM, Machado AS, Rocha-Silva F, Assunção CB, Graciele-Melo C, Costa LE, Portela

627 AS, Ferraz Coelho EA, Maria de Figueiredo S, Caligiorne RB.

628

629 Canine visceral leishmaniasis: Detection of Leishmania spp. genome in peripheral blood

Moshfe A, Mohebali M, Edrissian G, Zarei Z, Akhoundi B, Kazemi B et al. Canine visceral leishmaniasis: Asymptomatic infected dogs as a source of L. infantum infection. Acta 632 Tropica 2009; 112:101-105

633 Muller M, Schlangehauf P. Plasmodium knowlesi in travelers, update 2014. Int J Infect Dis 634 $2014 ; 22: 55-64$ 
635 Nagarajan P, Sloan BS. Isolated cutaneous leishmaniasis by Leishmania donovani in a soldier 636 returning from Afghanistan. American J Dermatopathol 2015; 37:591-592

637 Nevin RL. Mefloquine and posttraumatic stress disorder. In: Forensic and Ethical Issues in 638 Military Behavioral Health, PhD student thesis, John Hopkins School of Public Health, $639 \quad$ Baltimore MD

640 Nishiura H, Lee H, Uuan B, et al. Infectious disease risks among refugees from North Korea. Int 641 J Infect Dis 2018; 66:22-25

642 Obonaga R, Fernandez OL, Valderrama L, et al. Treatment failure and miltefosine susceptibility 643 in dermal Leishmaniasis caused by Leishmania subgenus Viannia species. Antimicrob

644 Agents Chemother. 2014;58(1):144-152

645 O'Donnell FL, Stahlman S, Fan M. Surveillance for vector-borne diseases among active and 646 reserve component service members, U.S. Armed Forces, 2010-2016.

647 MSMR 2018; 25:8-15

648 Oré M, Sáenz E, Cabrera R, et al. Outbreak of cutaneous leishmaniasis in Peruvian military 649 personnel undertaking training activities in the Amazon Basin, 2010. Am J Trop Med $650 \quad$ Hyg 2015; $93: 340-346$

651 Palatnik-de-Sousa CB, Silva-Antunes I, Morgado AA, et al. Decrease in the incidence of human 652 and canine visceral leishmaniasis after dog vaccination with leishmune in Brazilian

653 endemic areas. Vaccine 2009; 27:3505-3512

654 Park JE, Jung S, Kim A, Park JE. MERS transmission and risk factors: a systematic review. $655 \quad$ BMC Public Health 2018; 18:574 
656 Petersen CA. New means of canine leishmaniasis transmission in North America: the possibility

657 of transmission to humans still unknown. Interdiscip Perspect Infect Dis 2009;

658 2009:802712

659 Phasomkusolsil S, Kim HC, Pantuwattana K, Tawong J, Khongtak W, Schuster AL, Klein TA.

660 Colonization and maintenance of Anopheles kleini and Anopheles sinensis from the

661 Republic of Korea. J Am Mosq Control Assoc. 2014; 30:1-6

662 Portela ASB, Costa LE, Salles BCS, et al. Identification of immune biomarkers related to disease

663 progression and treatment efficacy in human visceral lesihmaniasis. Immunobiology

$664 \quad 2018 ; 223: 303-309$

665 Quinnell RJ, Courtenay O. Transmission, reservoir hosts, and control of zoonotic visceral

666 lesihmaniasis. Parasitology. 2009;136(14):1915-1934

667 Raad II, Chaftari AM, Dib RW, et al. Emerging outbreaks associated with conflict and failing

668 healthcare systems in the Middle East. Infect Control Hosp Epidemiol 2018; 13:1-7

669 Rahman K, Islam S, Tahman MW, et al. Increasing Incidence of Post-Kala-Azar Dermal

670 Leishmaniasis in a Population-Based Study in Bangladesh. Clin Infect Dis 2010;

$671 \quad 50(1): 73-76$

672 Rajapaske S, Rodrigo C, Fernando SD. Tafenoquine for preventing relapse in people with

673 Plasmodium vivax malaria. Cochrane Database Syst Rev 2015; 29:CD010458

674 Reithinger R, Dujardin JC, Louzir H et al. Cutaneous leishmaniasis. Lancet Infect Dis 2007;

$675 \quad 7(9): 581-596$

676 Rezvan H, Moafi M. An overview on Leishmania vaccines: a narrative review article. Vet Res

$677 \quad$ Forum 2015; 6(1):1-7

678 
679 Ribeiro RR, Michalick MSM, da Silva ME, et al. Canine Leishmaniasis: An overview of the 680 current status and strategies for control. Biomed Res Int. 2018; 3296893

681 Risueno J, Ortuno M, Perez-Cutillas P, Goyena E, Maia C et al. Epidemiological and genetic 682 studies suggest a common Leishmania infantum transmission cycle in wildlife, dogs, and 683 684 humans associated with vector abundance in Southeast Spain. Vet Parasitol 2018;

685

Robert LL. Malaria Prevention and Control in the United States Military. Medecine Tropicale 686 $2001 ; 61(1): 67-76$.

687

688 689 690 691 692 693 694 695 696 697 698 699 700 701

Rodriguez J, Maibach HI. Percutaneous penetration and pharmacoydynamics: wash-in and washoff of sunscreen and insect repellant. J Dermatolog Treat 2016; 27(1):11-18

Rosales-Chilama M, Gongora RE, Valderrama L, et al. Parasitological confirmation and analysis of Leishmania diversity in asymptomatic and subclinical infection following resolution of Cutaneous Leishmaniasis. PLoS Negl Trop Dis. 2015; 9(12): e0004273

Rowland T, Davidson SA, Kobylinski K, et al. Efficacy of permethrin treated bed nets against leishmania major infected sand flies. US Army Med Dep J 2015; 10-5

Ruh E, Bostanci A, Kunter V, Tosun O, Imir T, Schallig H, Taylan-Ozkan A. Leishmaniasis in northern Cyprus: Human cases and their association with risk factors. J Vector Borne Dis. 2017; 54(4):358-365

Salam N, Al-Shaqha WM, Azzi A. Leishmaniasis in the Middle East: incidence and epidemiology. PLoS Negl Trop Dis 2014; 8:e3208

Saroufim M, Charafeddine K, Issa G, Khalifeh H, Habib RH, Berry A, et al. Ongoing epidemic of cutaneous leishmaniasis among Syrian refugees, Lebanon. Emerg Infect Dis. 2014; $20: 1712-1715$ 
702 Shaha DP, Pacha LA, Garges EC, Scoville SL, Mancuso JD. Confirmed malaria cases among

703 active component U.S. Army personnel, January-September 2012. MSMR 2013; 20:6-7;

704 discussion 8-9

705 Schanz PM, Steurer FJ, Duprey ZH, et al. Autochthonous visceral leishmanaisis in dogs in North

706 America. JAVMA 2005; 226:1316-1322

707

708 major, L. tropica - as causative agents of mucosal leishmaniasis in Iran. Pathogens and

709 Global Health 2013; 107:267-272

710

Spelman JF, Hunt SC, Seal KH, Burgo-Black AL. Post Deployment Care for Returning Combat Veterans. Journal of General Internal Medicine 2012; 27:1200-1209

712 Stahlman S, Williams VF, Taubman SB. Incident diagnoses of leishmaniasis, active and reserve 713 components, U.S. Armed Forces, 2001-2016. MSMR 2017; 24(2):2-7

714 Stephens CR, Gonzalez-Salazar C, Sanchez-Cordero V, et al. Can you judge a disease host by 715 the company it keeps? Predicting disease hosts and their relative importance: a case study for leishmaniais. PLoS Negl Trop Dis. 2016; 10:e0005004

717 Stoeckle M, Holbro A, Arnold A, Neumayr A, Weisser M, Blum J. Treatment of mucosal leishmaniasis (L. infantum) with miltefosine in a patient with Good syndrome. Acta Tropica $2013 ; 128: 168-170$

720 Tan KR, Magill AJ, Parise ME, et al. Doxycycline for malaria chemoprophylaxis and treatment: report from the CDC expert meeting on malaria chemoprophylaxis. Am J Trop Med Hyg $2011 ; 84(4): 517-531$ 
723 Teimouri A, Mohebali M, Kazemirad E, Hajjaran H. Molecular identification of agents of human

724 cutaneous leishmaniasis in different areas of Iran using internal transcriber spacer 1 PCR-

725 RFLP. J Arthropod Borne Dis 2018; 12:162-171

726 Tenoro D, Green JA, Goyal N. Exposure-response analyses for tafenoquine after administration

727 for patients with Plasmodium vivax malaria. Antimicrob Agents Chemother 2015;

$728 \quad 59: 6188-6194$

729 Thomaidou E, Horev L, Jotkowitz D, Zamir M, Ingber A, Enk CD, Molho-Pessach V.

730 Lymphatic dissemination in cutaneous leishmaniasis following local treatment. Am J

$731 \quad$ Trop Med Hyg 2015; 93(4):770-773

732 Torres-Guerrero E, Quintanilla-Cedillo MR, Ruiz-Esmenjaud J, et al. Leishmaniasis: A review.

$733 \quad$ F1000Res. 2017; 6:750

734 Valencia SH, Ocampo ID, Arce-Plata MI, Recht J, Arevalo-Herrera M. Glucose-6-phosphate

735 dehydrogenase deficiency prevalence and genetic variants in malaria endemic areas of

736 Colombia. Malar J 2016; 15:291

737 Watson J, Taylor WRJ, Bancone G, Chu CS, Jittamala P, White NJ. Implications of current

738 therapeutic restrictions for primaquine and tafenoquine in the radical cure of vivax

739 malaria. PLoS Negl Trop Dis 2018; 12:e006440

740 Weil DN. Endemic Diseases and African Economic Growth: Challenges and Policy Responses. J

$741 \quad$ Afr Econ 2010;19(sup 3)

742 Weina PJ, Neafie RC, Wortmann G. Old world leishmaniasis: an emerging infection among

743 deployed US military and civilian workers. Clin Infec Dis 2004; 39:1674-1680

744 White NJ, Pukrittayakamee S, Hien TT, et al. Malaria. Lancet 2014; 383(9918):723-735 
745 Wollina U, Koch A, Guarneri C, Tchernev G, Lotti T. Cutaneous leishmaniasis;a case series 746 from Dresden. Open Access Maced J Med Sci 2018; 6:89-92

747 Wright NA, Davis LE, Aftergut KS, et al. Cutaneous leishmaniasis in Texas: a northern spread $748 \quad$ of endemic areas. J Am Acad Dermatol 2008; 58:650-652

749 Yiin LM, Tian JN, Hung CC. Assessment of dermal absorption of DEET-containing insect 750 repellent and oxybenzone-containing sunscreen using human urinary metabolites.

$751 \quad$ Environ Sci Pollut Res Inst 2015; 22:7062-7070

752 Yohannes D, Ketema T. Complicated malaria symptoms associated with Plasmodium vivax 753 among patients visiting health facilities in Mendi town, Northwest Ethiopia. BMC Infect

754 Dis. $2016 ; 16(1): 436$ 